\title{
Studi Sistem Pengelolaan PLTS 15 kW Stand Alone Dengan Metode Kano Di Dusun Yeh Mampeh Kabupaten Bangli
}

\author{
I G. A. Andita Putra, I A. D Giriantari, I N. S. Kumara
}

\begin{abstract}
Management of PLTS $15 \mathrm{~kW}$ stand alone at Yeh mampeh village, bangli regency implemented for PLTS can be utilized optimally and sustainable. Sistem management referring to the results of PLTS component with life time of that and results of the questionnaire. Questionnaire were taken by using Kano Method with 50respondent. Kano categoryused in this study are one dimensional, attractive, must be, indiferent, reverse. This method produces the desired management system of PLTS customers are workers will work twince in one week to four hours every day working with two workers, each employee is given a saary of $R$ p.300.000, PLTS depreciation is Rp. 3.896.000, with the expected quantity of PLTS customer 150th, so the contribution of each customer every mount is Rp. 28.000 . If this sistem can be running by society of Yeh Mampeh Village, then PLTS will be utilized optimally and sustainable.
\end{abstract}

Index Terms- Metode kano, Life Time, Komponen PLTS, Pelanggan PLTS

\begin{abstract}
Abstrak- Pengeloaan PLTS $15 \mathrm{~kW}$ stand alone di Desa Yeh Mampeh Kabupaten Bangli dilakukan agar PLTS dapat dimanfaatkan secara optimal dan berkelanjutan. Sistem pengeloaan mengacu kepada hasil perhitungan ekonomi komponen PLTS dengan life time komponen PLTS dan hasil kuesioner . Kuisioner diambil dengan menggunakan metode kano dengan 50 responden. Katagori kano yang digunakan pada penelitian ini adalah one dimensional, attractive, must be, indiferent, reverse. Metode ini menghasilkan sistem pengelolaan yang diinginkan masyarakat sebagai pelanggan PLTS yaitu pekerja akan bekerja 2 kali dalam satu minggu dengan 4 jam kerja setiap hari kerjanya dengan 2 orang pekerja, masing masing pekerja diberikan upah sebesar Rp. 300.000, penyusutan PLTS adaah Rp. 3.896.000 dengan jumlah pelanggan sesuai dengan yang diharapkan terpasang yaitu 150 pelanggan PLTS, maka iuran setiap bulan setiap pelanggan adalah Rp. 28.000 . Jika sistem ini dapat di jalankan oleh masyarakat Dusun Yeh Mampeh, maka PLTS akan dapat dimanfaatkan secara optimal dan berkelanjutan
\end{abstract}

Kata kunci- Video surveillance system, IP-camera, WebGIS

I G. A. Andita Putra adalah dengan Program Studi Magister Teknik Elektro, Program Pascasarjana, Universitas Udayana (e-mail: gungandita@gmail.com).

I A. D Giriantari adalah dengan Program Pasca Teknik Elektro Universitas Udayana (e-mail: dayu.giriantari@unud.ac.id).

I N. S. Kumara adalah dengan Program Pasca Teknik Elektro Universitas Udayana (e-mail: alit_bbc@yahoo.com).

\section{PEndahuluan}

$\mathrm{D}$ AERAH yang belum dapat terlayani listrik salah satunya adalah di Dusun Yeh Mampeh Kabupaten Bangli, hal ini terjadi karena sebagian penduduk di dusun ini tinggal dengan jarak yang berjauhan sehingga jauh dari jaringan listrik PLN. Kementerian Energi dan Sumber Daya Mineral (ESDM) memanfaatkan energi terbarukan yaitu energi matahari sebagai sumber pembangkit tenaga listrik. Pembangkit Listrik Tenaga Surya (PLTS) ini beroperasi mulai bulan Pebruari 2013 dengan luas lahan 3 are yang menghasilkan energi istrik sebesar $15 \mathrm{kWp}$. Tujuan pembangunan PLTS Yeh Mampeh ini adalah untuk memberikan pelayanan kepada konsumen energi listrik di Dusun Yeh Mampeh kepada 150 pelanggan yang belum terlayani listrik PLN, tetapi saat ini kondisi terpasang hanya pada 50 pelanggan.

Untuk melayani energi listrik secara berkelanjutan perlu adanya SOP sebagai acuan pengelolaan PLTS, namun saat ini belum ada SOP ataupun metode untuk pengelolaan PLTS. Perawataan dan pengelolaan dilakukan secara individu dan tidak ada acuan untuk mendapatkan biaya dari pelanggan PLTS tersebut, dimana biaya tersebut sangat penting untuk repair komponen yang rusak agar PLTS dapat melayani energi listrik secara berkelanjutan.

Penelitian ini akan membahas mengenai bagaimana sistem pengelolaan PLTS di Dusun Yeh Mampeh agar PLTS dapat dimanfaatkan secara optimal dan berkelanjutan. Metode yang digunakan dalam penelitian ini adalah Metode Kano. Metode Kano adalah satu model bertujuan mengkatagorikan atributatribut dari produk atau jasa berdasarkan seberapa baik produk atau jasa tersebut mampu memuaskan kebutuhan pelanggan . Metode ini digunakan pada penelitian ini bertujuan untuk dapat mengetahui harapan dan kepuasan masyarakat terhadap PLTS serta apa yang tidak diharapkan dan menjadi kekecewaan masyarakat secara bersamaan. Metode kano juga digunakan agar peneliti dapat mengidentifikasi jenis jenis pelayanan yang dianggap penting oleh pelanggan. Dengan menggunakan Metode Kano diharapkan PLTS dapat dikelola dengan baik sesuai harapan masyarakat dan mampu melayani energi listrik secara berkelanjutan..

\section{Metode Kano}

Noriaki Kano mengembangkan metode kano pada tahun 1984. Model Kano adalah model yang memiliki atribut- 
atribut yang dapat dikatagorikan kedalam sebuah produk atau jasa berdasarkan seberapa baik produk atau jasa tersebut mampu memuaskan kebutuhan pelanggan [1]. Metode kano memiliki beberapa atribut kano antara lain [2]:

1) Must Be

Persyaratan pada metode kano yang bersifat must-be adalah kriteria yang pemenuhannya hanya akan mencapai pernyataan "tidak mengecewakan". Persyaratan mustbedalam beberapa kasus justru dapat menentukan faktor kompetitif, yaitu dimana jika persyaratan ini tidak dipenuhi maka pelanggan tidak akan tertarik terhadap produk atau jasa tersebut dan pelanggan akan sangat kecewa. Namun saat pelanggan memerlukan produk atau jasa ini untuk kesenangannya, ternyata pemenuhan persyaratan ini tidak menaikkan kepuasan mereka.

2) One-Dimensional

Persyaratan One dimensional merupakan persyaratan dengan tingkatan pemenuhannya bersifat proporsional. Artinya, kepuasan pelanggan akan semakin menurun jika semakin rendah tingkat pemenuhannya dan jika semakin tinggi tingkat pemenuhannya, maka kepuasan pelanggan pun akan semakin tinggi. Persyaratan one dimensional ini biasanya diminta oleh pelangga secara eksplisit .

3) Attractive

Persyaratan attractive ini merupakan kriteria produk yang mempunyai pengaruh yang besar terhadap kepuasan pelanggan pada sebuah produk atau jasa. Persyaratan ini tidak diminta secara eksplisit oleh pelanggan dan tidak diharapkan oleh pelanggan. Pemenuhan persyaratan ini dapat memuaskan pelanggan lebih dari kepuasan yang proporsional terhadap produk atau jasa. Tetapi jika produk atau jasa tersebut tidak ada, tidak pula membuat pelanggan merasa kecewa.

4) Indifference

Persyaratan yang memiliki sifat Indifference merupakan kriteria produk atau jasa yang tidak akan menimbulkan reaksi apapun pada konsumen [3]. Kriteria ini merupakan kreteria yang biasanya bersifat netral.

5) Reverse

Persyaratan yang bersifat Reverse adalah kreteria yang bahkan akan menimbulkan ketidak puasan pada konsumen apabila dikembangkan dalam produk.

Bentuk kuisioner dari metode kano dengan atributatributnya adalah dengan menggunakan pertanyaan yang bersifat positif dan negatif. Pertanyaan akan ditanyakan sebanyak dua kali kepada responden [4]. Pertanyaan pertama memiliki sifat yang positif dan pertanyaan kedua memiliki sifat yang negatif (kebalikannya). Contohnya:

- Positif: Bagaimana jika terdapat pelayanan dengan pelayanan fitur 1 ?

- Negatif: Bagaimana jika tidak terdapat pelayanan dengan pelayanan fitur 1 ?

Kedua jawaban dari pertanyaan positif dan negatif ini kemudianakan dikombinasikan dalam tabel evaluasi agar fitur produk dapat digolongkan. Dari tabel tersebut dapat disimpulkan apakah kebutuhan pelanggan ini termasuk [2]:

$$
\begin{aligned}
& \mathrm{A}=\text { Attractive (Menarik) } \\
& \mathrm{M}=\text { Must-be (Harus Ada) } \\
& \mathrm{O}=\text { One-Dimensional (Satu Dimensi) } \\
& \mathrm{R}=\text { Reverse (Kebalikan) } \\
& \mathrm{I}=\text { Indifferent (Biasa Saja) }
\end{aligned}
$$

\begin{tabular}{|c|c|c|c|c|c|c|}
\hline $\begin{array}{l}\text { Kebutuhan } \\
\text { Pelanggan }\end{array}$ & & \multicolumn{5}{|c|}{ Pertanyaan } \\
\hline & & $S$ & $\mathrm{H}$ & $\mathrm{N}$ & $B$ & TS \\
\hline \multirow{5}{*}{$\begin{array}{l}\text { Pertanyan } \\
\text { Fungsional } \\
\text { (positif) }\end{array}$} & Suka & $\mathrm{O}$ & A & A & A & $\mathrm{O}$ \\
\hline & Harus & $\mathrm{R}$ & I & I & I & $\mathrm{M}$ \\
\hline & Netral & $\mathrm{R}$ & I & I & I & M \\
\hline & Boleh & $\mathrm{R}$ & I & I & I & M \\
\hline & TidakSuka & $\mathrm{R}$ & $\mathrm{R}$ & $\mathrm{R}$ & $\overline{\mathrm{R}}$ & $\mathrm{O}$ \\
\hline
\end{tabular}

TABEL I

TABel Evaluasi Metode KanO

Hasil pengisian kuisioner tersebut dihitung untuk setiap pertanyaan dari semua responden. Kesimpulan diambil dari jawaban yang paling banyak dipilih.

\section{A. Daftar Pertanyaan}

pertanyaan pada kuisioner akan disesuaikan dengan komponen-komponen fitur layanan yang diperlukan oleh pengguna model sehingga mampu mendapatkan tujuan survei terhadap konsumen. Setiap jawaban dari pertanyaan dikonversi ke dalam bentuk AMORI yaitu Must be, Onedimensional, Reverse, Indifferent, setelah mengkonversi kedalam bentuk AMORI, kemudian melakukan penghitungan jumlah masing-masing komponen $\mathrm{A}, \mathrm{M}, \mathrm{O}, \mathrm{R}$, , dan I untuk setiap pertanyaan. Dari hasil perhitungan ini, maka dapat kita hitung koefisien kepuasan konsumen dengan rumusan, diman koefisian tingkat kepuasan pelanggan berkisar antara 0 sampai dengan 1, semakin dekat dengan nilai 1 maka semakin mempengaruhi kepuasan konsumen, sebaliknya jika nilai mendekati ke 0 maka dikatakan tidak begitu mempengaruhi kepuasan konsumen [1].

$$
\text { Tingkat kepuasan }=\frac{\mathrm{A}+\mathrm{O}}{\mathrm{A}+\mathrm{O}+\mathrm{M}+\mathrm{I}}
$$

Tingkat kekecewaan, yaitu jika nilai semakin mendekati angka -1 maka pengaruh terhadap kekecewaan konsumen semakin kuat, sebaliknya jika nilainya 0 maka tidak mempengaruhi kekecewaan konsumen [1].

$$
\text { Tingkat kekecewaan }=\frac{\mathrm{A}+\mathrm{O}}{(\mathrm{A}+\mathrm{O}+\mathrm{M}+\mathrm{I}) \times(-1)}
$$

Tanda minus yang disimpan di depan koefisien tingkat kekecewaan konsumen adalah untuk menegaskan pengaruh negatif dari kepuasan konsumen pada kualitas produk yang tidak dipenuhi. 


\section{HASIL DAN PEMBAHASAN}

\section{A. Hasil Kuesioner dengan Metode Kano}

Metode pengambilan data dilakukan dengan cara kuesioner pada responden, yaitu data diperoleh dari hasil kuisioner dengan masyarakat Dusun Yeh Mampeh dan wawancara pada pihak pengelola atau perusahaan yang menjual sistem tersebut secara langsung. Wawancara dilakukan dengan mengajukan pertanyan-pertanyaan secara lisan maupun tulisan. Jumlah responden yang sekaligus menjadi pelanggan PLTS adalah 50 pelanggan.

Nilai dari setiap katagori kano dalam tiap-tiap atribut terhadap semua responden akan dijumlahkan, kemudian setelah didapatkan jumlah untuk setiap kategori kano di masing-masin atribut maka dapat ditentukan kategori Kano yang mendominasi tiap atribut dengan menggunakan Blauth"s formula. Blauth"s formula adalah sebagai berikut [5]:

1) Jika jumlah nilai (one dimensional + attractive + must be) $>$ jumlah nilai (indiferent + reverse) maka grade diperoleh nilai paling maksimum dari (one dimensional, attractive, must be).

2) Jika jumlah nilai (one dimensional + attractive + must be) $<$ jumlah nilai (indifferent + reverse) maka grade diperoleh yang paling maksimum dari (indifferent, reverse).

3) Jika jumlah nilai (one dimensional + attractive + must be) $=$ jumlah nilai (indifferent + reverse) maka grade diperoleh yang paling maksimum diantara semua kategori kano yaitu (one dimensional, attractive, must be dan indifferent, reverse).

4) Dari kategori Kano berarti jawaban yaitu $O$ (One dimensional) adalah Suka, M (must be) adalah Harus, I (indifferent) adalah Netral, A (attractive) adalah Boleh dan R (reverse) adalah Tidak suka.

Setelah menentukan requirement tertinggi dari masing masing item, selanjutnya hitung presentase dan Extent Of Satisfaction / Disatisfaction dari tiap item dengan menggunakan rumus sebagai berikut :

$$
\begin{gathered}
\text { Persentase }=\frac{\text { GRADE } \times 100 \%}{\text { TOTAL }} \\
\text { Extent of satisfaction }=\frac{\mathrm{A}+\mathrm{O}}{\mathrm{A}+\mathrm{O}+\mathrm{M}+\mathrm{I}} \\
\text { Extent of disatisfaction }=\frac{\mathrm{O}+\mathrm{M}}{(\mathrm{A}+\mathrm{O}+\mathrm{M}+\mathrm{I}) \times(-1)}
\end{gathered}
$$

Tingkat kepuasan pengguna tergantung pada koefisian tingkat kepuasan berkisar antara 0 sampai dengan 1, semakin dekat dengan nilai 1 maka semakin mempengaruhi kepuasan konsumen, sebaliknya jika nilai mendekati ke 0 maka dikatakan tidak begitu mempengaruhi kepuasan konsumen. Misalnya pada fitur no.1 (Tabel II ), nilai extent of satisfaction (EOS) yaitu 0,62. Hal ini menunjukkan bahwa jika fitur no.1 disediakan maka pengguna akan merasa puas.

Sedangkan, tingkat kekecewaan.dilihat dari nilai extent of dissatisfaction (EOD). Jika nilai semakin mendekati angka -1 maka pengaruh terhadap kekecewaan konsumen semakin kuat, sebaliknya jika nilainya 0 maka tidakmempengaruhi kekecewaan konsumen.Misalnya pada fitur no.1, nilai extent of dissatisfaction yaitu $-0,98$. Hal ini menunjukkan bahwa jika fitur ini tidak disediakan maka pengguna akan merasa kecewa. Perhitungan pada Tabel II dibawah pada fitur no.1 yaitu pelayanan energi listrik dari PLTS dapat melayani terus menerus adalah sbb :

$$
\begin{gathered}
\text { Persentase }=\frac{31 \times 100 \%}{50}=62 \% \\
\text { Extent of satisfaction }=\frac{0+31}{0+31+17+1}=0.63 \\
\text { Extent of disatisfaction }=\frac{31+17}{(0+31+17+1) \times(-1)}=-098
\end{gathered}
$$

Hal ini menunjukan bahwa jika pelayanan energi listrik dari PLTS disediakan maka masyarakat akan merasa puas, dan jika pelayanan energi listrik dari PLTS tidak disediakan maka masyarakat akan kecewa.

TABEL II

PERSENTASE DAN EXTENT OF SATISFACTION/DisATISFACTION

\begin{tabular}{lccc}
\hline \multicolumn{1}{c}{ Fitur } & Persentase & EOS & EOD \\
\hline $\begin{array}{l}\text { Pelayanan energi listrik PLTS secara } \\
\text { terus menerus }\end{array}$ & $62 \%$ & 0,63 & $-0,98$ \\
\hline $\begin{array}{l}\text { Keperluan memiliki teknis dan } \\
\text { pengurus untuk pemeliharaan PLTS }\end{array}$ & $56 \%$ & 0,64 & $-0,92$ \\
\hline $\begin{array}{l}\text { Keperluan penambahan Teknisi dan } \\
\text { pengurrus PLTS ( lebih dari 2 ) }\end{array}$ & $74 \%$ & 0,84 & $-0,09$ \\
\hline $\begin{array}{l}\text { Kemampuan Teknisi atau pengurus } \\
\text { tentang pengetahuan PLTS }\end{array}$ & $52 \%$ & 0,85 & $-0,38$ \\
\hline $\begin{array}{l}\text { Teknisi atau pengurus PLTS adalah } \\
\text { warga setempat }\end{array}$ & $44 \%$ & 0,52 & $-0,90$ \\
\hline $\begin{array}{l}\text { Teknisi atau pengurus PLTS diberi } \\
\text { gaji setiap bulan }\end{array}$ & $42 \%$ & 0,44 & $-0,49$ \\
\hline $\begin{array}{l}\text { Gaji setiap bulan untuk Teknisi atau } \\
\text { pengurus 450rb/bln/org atau lebih. }\end{array}$ & $62 \%$ & 0,34 & $-0,16$ \\
\hline Iuransetiapbulankurangdari 150rb/bln & $32 \%$ & 0,55 & $-0,21$ \\
\hline $\begin{array}{l}\text { Keperluan untuk mengelola hasil } \\
\text { iuran bulanan. }\end{array}$ & $38 \%$ & 0,51 & $-0,39$ \\
\hline $\begin{array}{l}\text { Pelayanan energi listrik dr PLTS } \\
\text { tidak dapat melayani terus menerus. }\end{array}$ & $48 \%$ & 0,14 & $-0,07$ \\
\hline $\begin{array}{l}\text { PLTS tidak memiliki Teknisi atau } \\
\text { pengurus untuk pemeliharaan PLTS }\end{array}$ & $56 \%$ & 0,03 & $-0,17$ \\
\hline $\begin{array}{l}\text { Jumlah Teknisi atau pengurus PLTS } \\
\text { tidak ditambahkan ( samadengan 2 })\end{array}$ & $42 \%$ & 0,69 & $-0,25$ \\
\hline $\begin{array}{l}\text { Teknisi atau pengurus PLTS tidak } \\
\text { memiliki Pengetahuan tentang PLTS }\end{array}$ & $42 \%$ & 0,13 & $-0,30$ \\
\hline $\begin{array}{l}\text { Teknisi atau pengurus PLTS bukan } \\
\text { warga setempat }\end{array}$ & $56 \%$ & 0,46 & $-0,07$ \\
\hline $\begin{array}{l}\text { Teknisi atau pengurus PLTS tidak } \\
\text { diberi gaji setiap ulan }\end{array}$ & $40 \%$ & 0,74 & $-0,43$ \\
\hline $\begin{array}{l}\text { Gaji setiap bulan Teknisi atau } \\
\text { pengurus dibawah 450rb/bln/org }\end{array}$ & $60 \%$ & 0,72 & $-0,09$ \\
\hline $\begin{array}{l}\text { Iuran setiap bulan lebih 150rb/bulan } \\
\text { Hasil iuran bulanan tidak dikelola }\end{array}$ & $48 \%$ & $52 \%$ & $-0,11$ \\
\hline & & 0,05 & $-0,24$ \\
\hline
\end{tabular}

Hasil survey yang diperoleh dari masyarakat Dusun Yeh Mampeh menggunakan Metode Kano dapat diketahui kesimpulan sesuai dengan tabel 2 di atas pada masing-masing fiturnya

\section{B. Pengelolaan Studi Ekonomi PLTS}

Setiap komponen PLTS memiliki karakteristik dan umur 
yang berbeda. Untuk memperoleh biaya yang dibutuhkan PLTS untuk dapat melayani masyarakat secara terus menerus, dapat dihitung dengan mengetahui harga komponen komponen utama PLTS dengan life time komponen tersebut.Dari total biaya dan life time setiap komponen, dapat diperhitungkan total penyusutan setiap bulan, seperti Tabel III dan IV dibawah ini.

TABEL III

BIAYA KOMPONEN DAN LIFE PLTS

\begin{tabular}{lccrr}
\hline \multicolumn{1}{c}{$\begin{array}{c}\text { Nama } \\
\text { Komponen }\end{array}$} & $\begin{array}{c}\text { Life } \\
\text { Time } \\
\text { (Thn) }\end{array}$ & $\begin{array}{c}\text { Harga / } \\
\text { Unit } \\
\text { (Rp.) }\end{array}$ & Unit & $\begin{array}{c}\text { Total } \\
\text { Biaya } \\
\text { (Rp.) }\end{array}$ \\
\hline Solar Panel 100 Wp & 25 & 1.500 .000 & 150 & 225.000 .000 \\
\hline Baterai 2V 1000 AH & 15 & 4.432 .500 & 72 & 319.140 .000 \\
\hline Inverter 5 Kw & 5 & 22.670 .000 & 3 & 68.010 .000 \\
\hline C.Controller 6,6 Kw & 5 & 4.790 .000 & 3 & 14.370 .000 \\
\hline \multicolumn{2}{c}{ Total Biaya Komponen PLTS } & & 626.520 .000 \\
\hline
\end{tabular}

TABEL IV

PENYUSUTAN SETIAP BULAN PADA PLTS

\begin{tabular}{lccc}
\hline $\begin{array}{c}\text { Nama } \\
\text { Komponen }\end{array}$ & $\begin{array}{c}\text { Life time } \\
\text { (thn) }\end{array}$ & $\begin{array}{c}\text { Harga } \\
\text { (Rp.) }\end{array}$ & $\begin{array}{c}\text { Penyusutan/bulan } \\
\text { (Rp.) }\end{array}$ \\
\hline Solar Panel 100 Wp & 25 & 225.000 .000 & 750.000 \\
\hline Baterai 2V 1000 AH & 15 & 319.140 .000 & 1.773 .000 \\
\hline Inverter 5 Kw & 5 & 68.010 .000 & 1.133 .500 \\
\hline C.Controller 6,6 Kw & 5 & 14.370 .000 & 239.500 \\
\hline \multicolumn{4}{r}{ Total Biaya Penyusutan } \\
\hline
\end{tabular}

Biaya penyusutan tersebut dapat digunakan sebaagai acuan untuk iuran yang di bebankan kepada masyarakat. Selain biaya penyusutan, harus dihitung pula gaji dari pengurus danteknisi PLTS untuk biaya pemeliharaan PLTS. Adapun pemeliharaan rutin tersebut, yaitu pada Tabel V.

TABEL V JADWAL PEMELIHARAAN PLTS

\begin{tabular}{|c|c|c|c|}
\hline Bagian & Jenis & Pemeliharaan & Waktu \\
\hline \multirow[t]{10}{*}{ PLTS } & \multirow[t]{2}{*}{ 1. Solar Panel } & $\begin{array}{l}\text { 1. Pembersihan permukaan } \\
\text { solar panel }\end{array}$ & 1 minggu \\
\hline & & $\begin{array}{l}\text { 2. Pemeriksaan pemasangan } \\
\text { instalasi }\end{array}$ & 2 minggu \\
\hline & \multirow[t]{3}{*}{$\begin{array}{l}\text { 2. Charger } \\
\text { Control }\end{array}$} & $\begin{array}{l}\text { 1. Pembersihan permukaan } \\
\text { charger control. }\end{array}$ & 1 minggu \\
\hline & & $\begin{array}{l}\text { 2. Pemeriksaan pemasangan } \\
\text { instalasi }\end{array}$ & 2 minggu \\
\hline & & $\begin{array}{l}\text { 3. Pemeriksaan pengaturan } \\
\text { operasi. }\end{array}$ & 2 minggu \\
\hline & \multirow[t]{2}{*}{ 3. Inverter } & $\begin{array}{l}\text { 1. Pembersihan permukaan } \\
\text { Inverter }\end{array}$ & 1 minggu \\
\hline & & $\begin{array}{l}\text { 2. Pemeriksaan pemasangan } \\
\text { instalasi }\end{array}$ & 2 minggu \\
\hline & \multirow[t]{3}{*}{ 4. Baterai } & 1. Pembersihan baterai & 1 minggu \\
\hline & & 2. Pemeriksaan instalasi & 1 bulan \\
\hline & & $\begin{array}{l}\text { 3. Pemeriksaan Tegangan } \\
\text { floating chaging pada baterai }\end{array}$ & 3 bulan \\
\hline \multirow[t]{2}{*}{ Sipil } & $\begin{array}{l}\text { 1.Lingkungan } \\
\text { sekitar PLTS }\end{array}$ & $\begin{array}{l}\text { 1. Pembersihan sampah } \\
\text { organic dan non organic }\end{array}$ & $\begin{array}{l}2 \text { kali/ } \\
\text { Minggu }\end{array}$ \\
\hline & $\begin{array}{l}\text { 2. Ruangan } \\
\text { System } \\
\text { kontrol }\end{array}$ & $\begin{array}{l}\text { 1. Pembersihan ruangan dari } \\
\text { debu dll }\end{array}$ & $\begin{array}{l}2 \mathrm{kali} / \\
\text { minggu }\end{array}$ \\
\hline
\end{tabular}

Dari penyusutan komponen dan gaji teknisi dan pengurus , maka total biaya yang harus dikumpulkan oleh masyarakat Dusun Yeh Mampeh sbb :

$$
\text { Rp. } 3.896 .000+\text { Rp. } 3.000 .000=\text { Rp.6.896.000. }
$$

Iuaran setiap bulan yang dibebankan ke 50 pelanggan PLTS sesuai dengan perhitungan penyusutan PLTS dan UMR Bangli sebagai upah dari pengurus dan teknisi sbb :

Rp. $6.896 .00: 50$ pelanggan $=$ Rp. $138.000 /$ bulan/ pelanggan .

\section{Pengelolaan Harapan Masyarakat dan Ekonomi PLTS}

Pengelolaan pada model 1 dengan kebutuhan biaya sesuai dengan Tabel VI, pekerja akan bekerja 2 kali dalam seminggu dengan 4 jam kerja setiap hari kerjanya dengan 2 orang pekerja. Sesuai UMR Bangli maka upah pegawai setiap orang setiap bulan yaitu Rp.300.000. Jumlah pelanggan sesuai dengan yang terpasang saat ini yaitu 50 pelanggan.

TABEL VI

PengelolaAn PLTS DENGAN Model 1

\begin{tabular}{|c|c|}
\hline Jenis Biaya & Kebutuhan Biaya (Rp.) \\
\hline Penyusutan PLTS & 3.896 .000 \\
\hline UpahPegawai (2 org) & 600.000 \\
\hline Total kebutuhanbiaya & 4.196 .000 \\
\hline Iuran/bulan/pelanggan & 84.000 \\
\hline
\end{tabular}

Pada model 2 dengan kebutuhan biaya sesuai dengan Tabel VII, pekerja akan bekerja 2 kali dalam seminggu dengan 4 jam kerja setiap hari kerja dengan jumlah 2 orang pekerja. Jumlah pelanggan yang terpasang saat ini yaitu 50 pelanggan dijumlah dengan penggunaan lampu jalan sebanyak 25 pelanggan sosial sehingga menjadi 75 pelanggan.

TABEL VII

PengelolaAn PLTS DENGAN Model 2

\begin{tabular}{lr}
\hline \multicolumn{1}{c}{ Jenis Biaya } & Kebutuhan Biaya (Rp.) \\
\hline Penyusutan PLTS & 3.896 .000 \\
\hline UpahPegawai (2 org) & 600.000 \\
\hline Total kebutuhanbiaya & 4.196 .000 \\
\hline Iuran/bulan/pelanggan & 56.000 \\
\hline
\end{tabular}

Pada model 3 dengan kebutuhan biaya sesuai dengan Tabel VIII, pekerja akan bekerja 2 kali dalam seminggu dengan 4 jam kerja setiap hari kerjanya dengan 2 orang pekerja. Jumlah pelanggan sesuai dengan yang diharapkan terpasang yaitu 150 pelanggan.

TABEL VIII

PENGelolaAn PLTS DENGAN Model 3 Jenis Biaya Kebutuhan Biaya (Rp.)

\begin{tabular}{lr}
\hline Penyusutan PLTS & 3.896 .000 \\
\hline UpahPegawai (2 org) & 600.000 \\
\hline Total kebutuhanbiaya & 4.196 .000 \\
\hline Iuran/bulan/pelanggan & 28.000 \\
\hline
\end{tabular}

\section{Kesimpulan}

Masyarakat menginginkan energi listrik dari PLTS dapat melayani masyarakat di Dusun Yeh Mampeh secara terus 
menerus, sehingga untuk mencapai harapan tersebut membutuhkan iuran yang dibebankan pada pelanggan. Mengacu kepada hasil perhitungan ekonomi komponen PLTS dan hasil kuesioner, bahwa masyarakat menginginkan iuran yang dibebankan pada pelanggan PLTS sekecil mungkin maka rekomendasi pengelolaan PLTS yaitu pada model 3. Iuran yang dibebankan pada pelanggan yaitu minimal sebesar Rp.28.000, dengan 150 pelanggan PLTS yang terpasang, namun sampai saat ini jumlah pelanggan yang terpasang hanya sebanyak 75 pelanggan. Pelanggan pribadi dan pelanggan sosial diberlakukan iuran dan pelayanan yang sama. Untuk iuran dari 50 pelanggan pribadi dibebankan pada warga masyarakat yang terlayani energi listrik PLTS dan iuran dari 25 pelanggan sosial dibebankan pada Banjar Yeh Mampeh, iuran dari penggunaan energi listrik dari PLTS ini diharapkan oleh masyarakat dapat dikelola oleh Banjar Yeh Mampeh. Setiap pelanggan menggunakan 3 lampu LED sebagai penerangan dengan penggunaan daya yang sudah dibatasi 100 Wh setiap $\mathrm{kWh}$ pelanggan sehingga untuk memaksimalkan penggunaan energi listrik yg diproduksi oleh PLTS sebesar 15 $\mathrm{kW}$ perlu mencari pelanggan baru sebanyak 75 pelanggan.

Pemeliharaan menjadi faktor penting dalam kinerja PLTS yang maksimal. Pemeliharaan rutin setiap minggu, setiap bulan dan setiap triwulan sesuai jadwal pemeliharaan yaitu 2 kali seminggu dengan 4 jam kerja setiap hari kerja, dimana pemeliharaan ini dilakukan oleh 2 orang teknisi yang sekaligus menjadi pengurus PLTS dan teknisi diharapkan berasal dari warga setempat yang diberi imbalan sebagai gaji Rp.300.000 setiap bulan.

Jika seluruh komponen pada model 3 diatas terpenuhi, maka setiap pelanggan hanya dibebankan iuran sebesar Rp.28.000 setiap bulan dengan kualitas PLTS yang maksimal dan masyarakat dapat menikmati pelayanan PLTS secara terus -menerus.

\section{DAFTAR PUSTAKA}

[1] Tiena G, Amran (2010). Pengukuran Kepuasan Pelanggan Menggunakan Metode Kano dan Root Cause Analysis. Jakarta Barat : Jurusan Teknik Industri, Universitas Trisakti .

[2] Widiawan, K. 2004. Pemetaan preferensi konsumen supermarket dengan metode kano berdasarkan dimensi servqual. Jawa Timur : Universitas Kristen Petra.

[3] Nurhayati, S. Analisis Kebutuhan Proses Bisnis Menggunakan Metode Kano. Bandung : Jurusan Teknik Komputer Fakultas Teknik dan Ilmu Komputer Universitas Komputer Indonesia Quaschning, V. 2005. Understanding Renewable Energy System. London : Earthscan.

[4] Fauzan Rifki, Mohammad (2011). Analisis Kualitas Pelayanan Terhadap Kepuasan Menggunakan Integrasi Metode Serqual dan Metode Kano. Semarang : Universitas Diponegoro

[5] Walden, D (1993). A Special Issue On Kano's Methods for Understanding Customer Defined Quality. The Center for Quality of Management Journal. Wordpress.com/Validitas dan reabilitas. 